\title{
O amanhã vai à mesa: abastecimento alimentar e COVID-19
}

\author{
The future at the kitchen table: COVID-19 and the \\ food supply
}

\author{
El futuro está sobre la mesa: COVID-19 y el \\ suministro de alimentos
}

Olivio José da Silva Filho 1
Newton Narciso Gomes Júnior 1

doi: 10.1590/0102-311X00095220
O Brasil tem vivenciado uma conjuntura delicada, por um lado uma crise em seu padrão de reprodução do capital, por outro, uma crise sanitária a partir do avanço da pandemia de COVID-19. A articulação dessas crises e a necessidade do isolamento social geram incertezas na satisfação das necessidades humanas em razão dos recuos nos rendimentos da população e a consequente queda no consumo, e o esgotamento da capacidade familiar de endividamento. A consequência mais imediata nesse cenário é o avanço da insegurança alimentar dada por restrições de renda que dificultam o acesso aos alimentos.

A pandemia global gerada pelo SARS-CoV-2 trouxe à tona as desigualdades sociais, como a ameaça ao Direito Humano à Alimentação Adequada, temática suprimida da agenda do Governo Federal nos últimos anos. O Estado como garantidor da segurança alimentar e nutricional vem perdendo relevância por meio da agenda neoliberal, enfraquecendo o já combalido papel das centrais de abastecimento e dos estoques públicos de alimentos, esfacelando o Programa de Aquisição de Alimentos (PAA) e suprimindo de vez as iniciativas de reforma agrária. Não bastasse tamanho arsenal de iniciativas antipopulares, no primeiro dia do governo Jair Bolsonaro o Conselho Nacional de Segurança Alimentar e Nutricional foi extinto sumariamente numa clara demonstração da irrelevância da questão alimentar para o Poder Executivo Federal.

O acesso aos alimentos está associado, diretamente, à regularidade da oferta dos produtos alimentares, à disponibilidade de renda nas mãos das pessoas e aos preços praticados no mercado varejista. A esses três fatores somam-se informações, hábitos e práticas alimentares; este arranjo é que determina o que, quanto e quando comprar.

Desde os anos 1980, o principal equipamento de varejo de alimentos é o supermercado. Operando em regime de vendas em escala, o autosserviço capturou a maior parte da demanda da sociedade para esses itens, difundiu novos padrões de consumo, ditou e subverteu práticas alimentares, e se organizou de sorte a atender qualquer segmento social independentemente da renda ou classe. Decorrente desse domínio, a rede capilar de varejo constituída de pequenos estabelecimentos convencionais, feiras livres, padarias e açougues, dentre outros, ou desapareceu ou tornou-se residual 1 no abastecimento da maior parte da população. Os equipamentos tradicionais que persistem tornaram-se uma forma de resistência à tendência à homogeneização dos serviços, convivendo também com a emergência de formas contemporâneas de abastecimento e comercialização mais setorizadas, principalmente de
1 Universidade de Brasília, Brasília, Brasil.

Correspondência

O. J. Silva Filho Rua 36 Sul, lote 19, apto. 1405, Brasília DF 71931-360, Brasil. olivioson@gmail.com 
circuitos curtos de alimentos, como as comunidades que sustentam a agricultura (CSAs), de cestas e feiras agroecológicas ou orgânicas, da agricultura urbana e periurbana e de outras formas de articulação entre agricultores e consumidores.

$\mathrm{Na}$ esteira do esvaziamento dos sistemas tradicionais de varejo emergiram vazios alimentares, ou em outros termos, territórios urbanos onde vivem populações econômica e socialmente vulneráveis e que já não dispõem de equipamentos de varejo ou feiras para se abastecer. Nesses casos, o acesso fica restrito às lanchonetes e lojas de conveniência sustentadas por vendas de alimentos e comidas inadequadas.

A necessidade do isolamento social afeta diretamente os rendimentos dos trabalhadores e a mobilidade, principalmente nos centros urbanos. Essa situação tende a enfraquecer o pouco que resta da rede capilar de varejo tradicional, contribuindo para a expansão dos vazios alimentares e as consequências a eles associadas, como visto anteriormente.

Dessa forma, a crise sanitária pode reforçar a tendência de aumento do consumo de ultraprocessados no Brasil em relação aos alimentos socialmente referenciados 2,3. A Pesquisa de Orçamentos Familiares (POF) de 2017-2018 4, utilizando a classificação NOVA 5,6, identificou o aumento da participação dos ultraprocessados no total de calorias determinado pela aquisição alimentar, de 12,6\% em 2002-2003 para 18,4\% na edição atual da pesquisa, já os alimentos in natura ou minimamente processados passaram de $53,3 \%$ da composição para 49,5\%. Esses dados vão ao encontro de uma pesquisa recentemente publicada 7 , demonstrando que os preços dos alimentos ultraprocessados estão ficando mais baratos e devem igualar o preço dos alimentos in natura ou minimamente processados em 2026. Em 2030, esses pseudoalimentos custarão, pela projeção, $\mathrm{R} \$ 4,34$ por quilo e estarão $\mathrm{R} \$ 0,90$ mais baratos que o quilo dos alimentos in natura ou minimamente processados.

Entre a segunda quinzena de março e a primeira de abril, mesmo período em que foi intensificado o isolamento social, já podem ser revelados os efeitos da pandemia nos preços dos alimentos no Brasil. De acordo com o Índice Nacional de Preços ao Consumidor Amplo-15 - IPCA-15 (Instituto Brasileiro de Geografia e Estatística. https://sidra.ibge.gov.br/home/ipca15, acessado em 01/Mai/2020), no período mencionado o Índice Geral de Inflação marcou -0,01\% e a alimentação nos domicílios, 3,14\%. No tocante ao universo de alimentos analisados pelo IPCA-15, destaca-se o aumento dos grupos de alimentos com média superior aos dos domicílios, sendo os tubérculos, raízes e legumes em 22,1\%, hortaliças e verduras em $11,89 \%$, frutas em $8,84 \%$, sal e condimentos em 5,51\%, leites e derivados em $3,77 \%$ e cereais, leguminosas e oleaginosas em 3,59\%. Observou-se nesse intervalo, por intermédio do índice, o aumento dos preços dos alimentos in natura ou minimamente processados em relação à média dos alimentos em domicílios e em relação aos outros grupos de alimentos da classificação NOVA; e os alimentos ultraprocessados apresentaram uma inflação menor do que a média dos alimentos em domicílio.

O sistema de abastecimento alimentar brasileiro não tem dado sinais de desabastecimento generalizado de produtos, mas a assimetria entre os rendimentos e os preços praticados reforçará uma situação de insegurança alimentar, que não será resultado da falta de alimentos em si, mas da sua forma como comida/mercadoria. Pode-se estabelecer, portanto, a tendência à constituição de hábitos alimentares inadequados por essa assimetria, mas também os ultraprocessados podem se tornar mais presentes na mesa da população em que seus rendimentos são suficientes para a manutenção de sua vida e de seu consumo, por meio da associação destes alimentos à ideia de conforto e prazer, como um alento aos efeitos da pandemia.

A COVID-19 tem relevado a perversidade da gestão do Estado na garantia dos direitos e das necessidades humanas básicas nos últimos anos, e reforçado a ineficiência das políticas neoliberais para o seu enfrentamento, contribuindo para o avanço da inadequação da alimentação e da insegurança alimentar. Em meio à pandemia, as ações do Governo Federal estão aquém das dificuldades que estão sendo enfrentadas pela população brasileira mais vulnerável, como o Auxílio Emergencial 8, cujo montante não assegura as necessidades básicas de moradia, higiene e alimentação. Cabe salientar que a forma como está sendo operacionalizado esse Decreto tem excluído parte da população que não tem acesso aos meios de cadastro ou que possuam dificuldades em realizá-lo. Outros fatores que têm sido noticiados são a dificuldade de mulheres provedoras de família para o recebimento de duas cotas, a demora na análise das informações cadastradas, a dificuldade de cadastramento de pessoas com irregularidades no Cadastro de Pessoas Físicas (CPF) e a aglomeração em bancos para o recebimento 
do benefício. Outras medidas que reforçam esse descompromisso com a manutenção da vida foram a aprovação da Medida Provisória no 9279 e a tentativa de retomar e aprovar a Medida Provisória no 905 10, que atentam contra os direitos trabalhistas, e a aprovação da Medida Provisória no 957 11, que de forma já tardia e com verbas reduzidas, delonga a execução da compra de alimentos da agricultura familiar por meio do PAA, o que compromete a garantia da venda de agricultores e a segurança alimentar e nutricional de beneficiários que já poderiam estar sendo atendidos por esta política.

Em meio a esse cenário de enfraquecimento do papel do Estado, principalmente do Poder Executivo Federal, movimentos sociais, sindicatos, universidades, partidos políticos, organizações sociais e associações têm reforçado a dimensão da solidariedade em defesa da vida, com base em ações que atendam as necessidades materiais e também de conscientização das medidas de enfrentamento ao vírus e dos direitos das famílias. Ações como pesquisas para a construção de respiradores, a confecção de máscaras de proteção e de álcool em gel têm sido estimuladas nas universidades; campanhas de arrecadação de cestas básicas de alimentos e de itens de higienização para famílias em vulnerabilidade social; a doação de alimentos agroecológicos para famílias, escolas e instituições provindos de áreas da reforma agrária; a doação de marmitas, sopas e cafés da manhã para a população em situação de rua; a doação de leite, alimentos, materiais de higiene e de equipamentos de proteção individual (EPI) para hospitais; a venda de alimentos agroecológicos a preços populares; e o estímulo à participação de CSAs e de cestas de agroecológicas são alguns exemplos que estão sendo cada vez mais comuns em diversas cidades brasileiras.

A solidariedade e a ajuda mútua são ferramentas históricas das relações sociais da periferia e do campesinato. Em tempos de COVID-19 tornaram-se ações essenciais para a mitigação dos efeitos já sentidos desde o início da pandemia. Mesmo que as ações não tenham o alcance dos desafios da população, as ações e a conscientização vão ao encontro da defesa do Direito Humano à Alimentação Adequada e da necessidade de articulação entre a sociedade civil e o Estado, em todos os seus níveis, na construção de políticas públicas e de comitês populares capazes de garantir a segurança alimentar e nutricional, a renda, a saúde e a segurança sanitária, de forma emergencial e continuada.

As crises também demonstram o esgotamento do neoliberalismo e do atual modelo hegemônico do sistema alimentar brasileiro na manutenção da vida e da alimentação, colocando em xeque a comida/mercadoria, cada vez mais cara, globalizada e ultraprocessada, problemas estruturais que só serão solucionados a partir da construção de um sistema alimentar que privilegie as dimensões da soberania e segurança alimentar e nutricional; que reforce as formas tradicionais e as novas formas de abastecimento e comercialização; e que promova uma reeducação alimentar dos comensais em todas as dimensões do comer.

\section{Colaboradores}

Ambos os autores contribuíram com a concepção, análise, redação e revisão do artigo.

\section{Informações adicionais}

ORCID: Olívio José da Silva Filho (0000-00019146-9928); Newton Narciso Gomes Júnior (00000002-1455-7729).

\section{Referências}

1. Gomes Junior NN, Pinto HS, Leda LC. Alimento e comida: sistema de abastecimento e consumo alimentar urbano. Guaju 2016; 2:61-76.

2. Louzada MLC, Martins APB, Canella DS, Baraldi LG, Levy RB, Claro RM, et al. Alimentos ultraprocessados e perfil nutricional da dieta no Brasil. Rev Saúde Pública 2015; 49:38.

3. Organização Pan-Americana da Saúde. Alimentos e bebidas ultraprocessados na América Latina: tendências, efeito na obesidade e implicações para políticas públicas. Brasília: Organização Pan-Americana da Saúde; 2018. 
4. Instituto Brasileiro de Geografia e Estatística. Pesquisa de Orçamentos Familiares 2017-2018: avaliação nutricional da disponibilidade domiciliar de alimentos no Brasil. Rio de Janeiro: Instituto Brasileiro de Geografia e Estatística; 2020.

5. Monteiro CA, Cannon G, Lawrence M, Louzada MLC, Machado PP. Ultra-processed foods, diet quality, and health using the NOVA classification system. Rome: Food and Agriculture Organization of the United Nations; 2019.

6. Monteiro CA, Cannon G, Levy RB, Moubarac JC, Louzada ML, Rauber F, et al. Ultra-processed foods: what they are and how to identify them. Public Health Nutr 2019; 22:936-41.

7. Gomes EM, Passos CM, Levy RB, Martins APB, Mais LA, Claro RM. What to expect from the price of healthy and unhealthy foods over time? The case from Brazil. Public Health Nutr 2020; 23:579-88.

8. Brasil. Decreto no 10.316, de 7 de abril de 2020. Regulamenta a Lei no 13.982 , de 2 de abril de 2020, que estabelece medidas excepcionais de proteção social a serem adotadas durante o período de enfrentamento da emergência de saúde pública de importância internacional decorrente do coronavírus (Covid-19). Diário Oficial da União 2020; 7 abr.
9. Brasil. Medida Provisória no 927, de 22 de março de 2020. Dispõe sobre as medidas trabalhistas para enfrentamento do estado de calamidade pública reconhecido pelo Decreto Legislativo no 6, de 20 de março de 2020, e da emergência de saúde pública de importância internacional decorrente do coronavírus (Covid-19), e dá outras providências. Diário Oficial da União 2020; 22 mar.

10. Brasil. Medida Provisória no 905, de 11 de novembro de 2019. Institui o Contrato de Trabalho Verde e Amarelo, altera a legislação trabalhista, e dá outras providências. Diário Oficial da União 2019; 11 nov.

11. Brasil. Medida Provisória no 957, de 24 de abril de 2020. Abre crédito extraordinário, em favor do Ministério da Cidadania, no valor de $\mathrm{R} \$ 500.000 .000,00$, para fim que especifica. Diário Oficial da União 2020; 27 abr.
Recebido em 23/Abr/2020

Versão final reparesentada em 07/Mai/2020 Aprovado em 11/Mai/2020 